\title{
Retraction Note to: Evolution of the Health of Concrete Structures by Electrically Conductive GFRP (Glass Fiber Reinforced Plastic) Composites
}

\author{
Soon-Gi Shin ${ }^{1}$
}

Published online: 26 February 2018

๑) The Korean Institute of Metals and Materials 2018

\section{Retraction Note to: Metals and Materials International, Vol. 8, No. 1, pp. 63-68 (2002) https://doi.org/10.1007/bf03027029}

This article [1] has been retracted at the request of the Editor-in-Chief. Concerns were raised regarding substantial duplications with previous articles published in other journals in which for some S.-G. Shin is one of the co-authors. After a thorough analysis we conclude that the concerns are valid. The article contains sections that substantially overlap with the following published article [2] (amongst others). S.-G. Shin has not responded to correspondence from the Editor about this retraction.
1. "Evolution of the Health of Concrete Structures by Electrically Conductive GFRP (Glass Fiber Reinforced Plastic) Composites" S.-G. Shin, Mat. Mater. Int., Vol. 8, Issue 1, pp. 63-68 (2002).

2. "Application of self-diagnosis FRP to concrete pile for health monitoring" H. Nishimura, T. Sugiyama, Y. Okuhara, S.-G. Shin, H. Matsubara, and Hiroaki Yanagida, Proc. SPIE 3985, Smart Structures and Materials 2000: Smart Structures and Integrated Systems, pp. 335-342, Society of Photo Optical, USA (2000).
The original article can be found online at https://doi.org/10.1007/BF03027029.

Soon-Gi Shin

ssg@ kangwon.ac.kr

Division of Metallurgical and Materials and Chemical

Engineering, Dong-A University, 840 Hadan 2-dong,

Saha-ku, Busan 604-714, Korea 